\title{
Macedonio y el Humor de Julio Cortázar
}

Le résultat, qui tourne au paradoxe en est, donc, que dans la fiction bien des choses ue sont pas eirangement inquiétantes gui le seraient si elles se passatent dans la vie, et qu, dans la fiction, il existe bien des moyens de provoquer des effets d'inquiétante étrangeté qui, dans la vit, z'existent pas.

Sigmund Freud, "L'inquiétante étrangeté", Das Unbeimlicbe.)

Como no soy susceptible le expliqué en detalle que babia descubierto la mosca en la página 231 de Oliver Twist con puertas y ventanas cerradas, y que al levantar la vista justo en el momento en que el maligno Sykes iba a matar a la pobre Nancy, vi tres moscas que vo. laban cerca del cielo raso, y una de las moscas volaba patas para arriba.

(Julio Cortázar, Ultimo round).

Con Historias de cronopios y de famas Julio Cortázar inicia una aventura humoristica cuyas proyecciones extremas pueden verse en sus obras más recientes: La vuelta al dia en ochenta mundos, Ultimo round $y$ en algunas secciones de 62. Modelo para armar. El sustrato material de esta aventura está formado por juegos con el lenguaje que tienden a cuestionar las categotías de espacio, tiempo y causalidad. Complementariamente plantean una crítica al sentido común y un desafio a la solemnidad. Esta última función es para Cortázar, fundamental. En La vinelta al dia en ocbenta mundos hay un texto titulado "De la seriedad en los velorios" donde Cortázar se refiere explícitamente a la importancia que el humor tiene para él:

Le aclaro entonces que el humor cuya alarmante carencia deploro en nuestras tierras reside en la situación física y metafísica del escritor que le permite lo que para otros serian errores de paralaje, por ejemplo ver las agujas del reloj del comedor en la una 
y media cuando apenas son las doce y veinticinco, y jugar con todo lo que brinca de esa fluctuante disponibilidad del mundo $y$ sus criaturas, entrar sin esfuerzo en la ironia, el understatement, Ia ruptura de los clisés idiomáticos que contamina nuestras mejores prosas tan seguras de que son las doce y veinticinco como si las doce $y$ veinticinco tuvieran alguna realidad fuera de la convención que las decidió con gran concurso de cosmógrafos y pendolistas de Maguncia y de Ginebra. ${ }^{1}$

Cortázar habla aquí de la inexistencia del humor tadical que propone: un humor que plantee la subversión del sentido común $\mathrm{y}$ construya la posibilidad de percibir el carácter convencional, atbitrario, de un mundo aceptado como incuestionable. Estas afirmaciones podrían hacer pensar que Cortázar trabaja con una perspectiva nueva, inédita, separado de una tradición literaria. Peto, no obstante, su gesto tiene precedentes en la literatura de su país ${ }^{2}$ y Cortázar es consciente de ello: una de las páginas del texto que citamos consiste de una fotografía de Macedonio Fernández tocando la guitarra. Además de las referencias a Macedonio hay otras a Marechal y a Bioy Casares. Estas figuras son, para Cortázar, ejemplo de la perspectiva humoristica que él mismo asume. La literatura de Macedonio aparece en sus escritos y en los de Marechal y Bioy Casares como programa y problemática realización de un humorismo radical y consecuente. A pesar de este reconocimiento la obra de Macedonio Fernández no ha sido estudiada con la profundidad que merece. Trataremos de establecer aquí un grupo de características del humor de Macedonio Fernández que aparecen también en Cortázar fundamentando, así, su influencia sobre las obras de Cortázar que nos ocupan.

En un texto titulado "Para una teoría de la Humorística", s Macedonio Fernández trata de elaborar una teoría acerca del humor. Fundamenta alli una crítica al humor realista, basado en situaciones de la vida real. Su objetivo es conseguir un humor conceptual, sin dependencia con respecto a la realidad no literaria. El propósito principal de esta "Ilógica", como él la llama, es crear un ámbito de "nada".* Esta "nada"

1 Julio Cortázar, La vuelta al día en ochenta mundos (México: Siglo XXI, 1967), pp. 35-36.

2 La relación de su actitud con otras literaturas, por ejemplo la francesa, es evidente y reconocida por el propio Cortázar. Las numerosas menciones a participantes en el movimiento Dada y la recurrencia de comentarios admirativos acerca de Maroel Duchamp y Man Ray, por ejemplo, atestiguan el parentesco.

${ }^{3}$ Macedonio Fernández, "Para una teoría de la Humorística", en Papeles de recienvenido' (Buenos Aires: Losada, 1944).

* Ana María Barrenechea ha estudiado algunos recursos de creación de la 
califica a un contexto literario opuesto al realismo. Tiene como función eliminar la confianza en el sentido común, minar la creencia en las convenciones. Veamos algunas de las reglas del juego destructivo de Macedonio.

\section{MACEDONIO Y LA SUBVERSION DEL SENTIDO COMUN}

Macedonio efectúa la subversión del orden real en tres aspectos que para él eran los esenciales: el tiempo, el espacio y la causalidad. Por medio de esta subversión crea un mundo del no-ser, de nada. Sus recursos son claros pero no se convierten en receta ni mero juego. Es un juego, sin embargo, por medio del cual se busca la creación de una textura literaria que permita la entrada del lector en un mundo fan* tástico.

\section{A. EL ESPACIO}

Macedonio habla repetidamente de crear una nada que ocupe lugar, una ausencia que gravite sobre el mundo real, un vacio presente por su ausencia. Realiza esta ausencia multiplicada y clara al aplicar la adición a términos que en general no la admiten:

Lo que tengo que explicarle es la gran ventaja, placer aparte, que me aportaba su fiesta. Fuera de usted y yo, nadie ha escrito menos en menos tiempo. Sólo nosotros podíamos superarnos: si el tiempo disponible hubiera sido menos; sólo si hubiera sido ninguno no nos sería posible haber escrito menos que nadie en tiempo ninguno. (PR, P. 68)..$^{3}$.

El mecanismo de adición aplicado repetidamente al haber escrito menos crea un espacio donde se compite por la ausencia.

El estar presente en algún lado alimenta simultáneamente las múltiples exclusiones de lugares donde esa presencia no se concreta. De tal modo, estar incluye un no-estar siempre más gigantesco que el pri-

nada en la obra de Macedonio Fernández en su trabajo, "Macedonio Fernández y su humorismo de la nada", Buenos Aires Literaria, No. 9 (junio de 1953) p. $25 \mathrm{y}$ ss.

5 Usamos la abreviatura PR para referirnos a: Macedonio Fernández, Papeles de recienvenido (Buenos Aires: Centro Editor de América Latina, 1966), y MNE para Macedonio Fernández, Museo de la novela de la Eterna (Buenos Aires: Centro Editor de Amética Latina, 1967). 
mero: La literatura de la presencia es sustituida por Macedonio por una literatura de la ausencia que tiende a presentar el espacio vacio:

No necesita explicación mi presencia aquí, señores, pues que esta falta; y espero que seréis con ella indulgentes, considerando que no se ha producido. Puedo demostraros punto por punto que corristeis casi todo el peligro de tenerme en Córdoba; y no hay que fiarse en que no estoy, como si fuera fácil conseguir mi ausencia, tan solicitada, ni os enorgullezcáis de que "dicho señor Fernández" no esté en Cótdoba, pues en ello no os he dispensado ninguna particular preferencia. Hoy, excepto Buenos Aires, toda ciudad argentina of rece tal aliciente, $y$ aún creo que mi ausencia- se ha extendido a puntos del extranjero, en que jamás he estado, por efecto del concepto que de mí se difunde. (PR, Pp. 52-53).

La ausencia es activa, un dinámico no-estar que merece ser notado, puesto de relieve. Macedonio ataca sistemáticamente las familiares ideas de ubicación en un espacio determinado. Al tomar la situación de manera opuesta a la que exigiría el sentido común, establece un ámbito donde lo importante es el escamoteo y no la presencia. Los ataques a la geografia ${ }^{6}$ y a otras determinaciones espaciales se multiplican en su obra siempre con el mismo sentido: creación de un absurdo conceptual. ${ }^{7}$

Julio Cortázar crea a menudo absurdos espaciales al estilo de Macedonio. Uno de los textos donde esto sucede de manera bastante obvia es en "Me caigo y me levanto"8 donde la repetición de "recaer" y "rehabilitar" destruyen toda posibilidad de determinación espacial. Esta imposibilidad inicia el texto y aumenta por grados, como sucede asiduamente en la prosa de Macedonio:

Nadie puede dudar de que las cosas recaen. Un señor se enferma, y. de golpe un miércoles recae. Un lápiz en la mesa recae seguido. Las mujetes, cómo recaen. Teóticamente a nada o a nadie se le ocurriría recaer pero lo mismo está sujeto, sobre todo porque recae

- Ver como ejemplo los siguientes textos: "Carta abierta argentino-uruguaya" (PR, p. 44); "Querido Jorge Luis" (PR, p. 90); "Boletería da la gratuidad", (PR, p. 37); "La oratoria del hombre confuso", (PR, P. 60).

7 A veces este absurdo espacial es creado por la otorgación de atributos poco corrientes a ciertos elementos. En ese sentido es muy ilustrativo el ejemplo de una carta que Macedonio escribió para Borges. Allí atribuye a una calle posibilidades de autodeterminación, desaparíción y crimen. (Ver la edición ya citada de 1944 de Papeles de recienvenido, p. 10-11).

8 En La vielta al dia a., Pp. 39-40; 
sin conciencia, recae como si nunca antes. Un jazmín para dar un ejemplo perfumado. A esa blancura, de dónde le viene su penosa amistad con el amarillo? El mero permanecer es recaída: el jazmín, entonces. $\mathrm{Y}$ no hablemos de las palabras, esas recayentes deplorables, ni de los buñuelos fríos, que son la recaída clavada.9

Otro de los recursos observables en la prosa de Macedonio es la amplificación de una idea inicial ocasionändo, así, un absurdo. ${ }^{10}$ Cortázar juega del mismo modo con el espacio en varios momentos. Uno de ellos ocurre en.Ultimo round:

Procederé de la manera siguiente: Primero me pondré mi corbata amarilla, y después de haber elegido la más esbelta y vivaz de mis hormigas, la soltaré para que se pasee por la corbata. Habrá así un doble paseo, en el que yo iré y vendré frente a la casa del señor Silicoso y mi hormiga irá y vendrá por mi corbata. He dicho un doble paseo? Más bien una apertura de paseos en espiral, pues si bien la hormiga se pasea por mi corbata, mi corbata se pasea conmigo, la tierra me pasea en torno de la eclíptica, ésta se pasea a lo largo de la galaxia, que se pasea en torno de la estrella Beta del Centauro. ...11

Los ejemplos de creación de absurdos por medio de la excesiva generalización de una idea que de por sí y en el nivel correspondiente parece razonable y posible, abundan en las obras de nuestros dos autores. Encontramos numerosas ocasiones en que Cortázar elabora estos mecanismos para jugar con el espacio. Un texto de Historia de cronopis y de famas, "Instrucciones para subir una escalera"12 es muy ilustrativo al respecto.

En la literatura de Macedonio, los juegos con el espacio tienden a burlarse de la escritura. El sentido principal de esta burla es un cuestionamiento de la existencia de lo leido. Veamos un ejemplo:

En los días en que toda la literatura es: "Señor, habiéndose derretido la ley de alquileres, prefiera usted, desde hoy, en esta su

- La vuelta al dia..., p. 39.

10 Ver el texto titulado "Aqui es el boliche remendón de 'La perfecta descompostura" ", en PR, P. 166. baja.

${ }_{11}$ Julio Cortázar, úlitimo round (México: Siglo XXI, 1969), p. 80, planta 12 Julio Cortázar, Historias de cronopios y di famas (Buepos Aires: Edicio. nes Minotauro, 1966), Pp. 25.26, 
casa por esa mi casa, pagarme 80 pesos más, etc', me dirigí a Marlin Fierro pidiéndole me aumentaran espacio para los escritos. Con tal mala suerte que se me contestó mandara sólo artículos cercados o sea, contenidos por un cerco y que tuvieran la solución cerca, y además, que ocuparan un solo lugar. De modo que no he podido saber qué gusto tiene un aumento, cuando toda la población lo sabe. ( $P R$, p. 42)

La palabra "cerco" con sus múltiples alusiones contribuye a crear una duda general acerca de la ubicación, una inquietud con respecto a lo leido. Este es uno de los aspectos en los cuales la literatura de Macedonio se autointerroga. El humor acerca del acto de escribir y de leer que aparece recurrentemente en su obra es una de las maneras en que ésta revela su carácter autorreflexivo. Se trata de no aceptar los supuestos para cuestionar la naturaleza del lenguaje literario. El propósito de conmover toda fe en la lógica pasa por el de hacer dudar de lo visto, de aquello en estado de escribirse. La burla de Macedonio abarca tanto al que lee $y$ al que escribe como al espacio concreto donde esa obra existe. La cantidad de prólogos que dedica a estas burlas en Museo de la novela de la Eterma $^{13}$ testimonia su interés por hacer consciente al lector de los mecanismos por los cuales la ficción literaria se hace posible. Una burla recurrente en sus escritos es la dedicada al lector de contenidos, que toma las palabras por las cosas y pretende encontrar verdades extraliterarias en lo que lee:

Me parece que yo hago como todos (dicen que el tartamudo cree que todos son de su tartamución. Me gusta más el dicho "el ladrón cree que todos son de su condición" porque es aconsonantado, y es un placer tan grande leer "ón" y unos segundos después otra vez "ón". Sólo así el dicho contiene sabiduria). (PR, p. 41).

Para Macedonio es una tontería creer en la enseñanza literal de lo escrito. Hay más sabiduría en un dicho aconsonantado que en unas palabras pretendidamente sabias. La sabiduría de la literatura es otra. Consiste, sobre todo, en la falta de solemnidad, presupuesto indispensable

13 En esta obra Macedonio escribe más de cincuenta prólogos cuya función es ejecutar la burla acerca de la literatura para crear una nueva lucidez en el lector. El cuestionamiento sistemático del argumento, la naturaleza de los personajes, los mecanismos de proyección del lector y los mecanismos de escribir del autor, impregna los prólogos. Existe alli un cuestionamiento radical del terreno. espacio ... en el cual la literatura se hace posible. 
para la creación de una obra lúcida. En el humor y los juegos de palabras de Macedonio Fernández hay una crítica a la solemnidad que fructifica en una literatura de paradojas e incongruencias. Su humor desrealizador cuestiona la existencia del espacio literario para destruir el espítitu de seriedad en el lector y prepararlo, así, para participar en una aventura espiritual. ${ }^{14} \mathrm{La}$ lucidez que pretende crear en los lectores abarca también la existencia material del libro. En Museo de la novela de la Eterna son numerosas las menciones al formato del libro, sus tapas, la función de los blancos, la tipografía, las posibilidades de variación de la lectura. En Papeles de recienvenido se menciona distintas alternativas para leer la obra, se comenta acerca de los lectores y se elabora, en fin, el simulacro de un diálogo entre el autor y su público.

Cortázar retoma y lleva a resultados más extremos esta meditación acerca de la organización del espacio material del libro. En Rayuela propone dos lecturas diversas y sugiere que una de ellas es prescindible. En La Vuelta al dia en ochenta mundos arma un libro con materiales heterogéneos dentro de una estructura que sugiere la libre combinación y critica, implicitamente, la división de la literatura en géneros. Ultimo round es un libro partido en dos plantas con varias posibilidades de lectura y combinación. 62. Modelo para armar sugiere una lectura lineal, pero alli existe el imperativo de una combinación a nivel de sentido: "...el armado a que se alude es de otra naturaleza, sensible ya en el nivel de la escritura donde recurrencias y desplazamientos buscan liberar de toda fijeza causal, pero sobre todo en el nivel del sentido donde la apertura a una combinatoria es más insistente e imperiosa". ${ }^{15}$

Para Macedonio la burla del espacio donde la literatura se hace posible, debe ser complementada por la desaparición del autor individual. Este es sustituido por una escritura sin autores, un continuo que se realiza en forma colectiva. ${ }^{16}$ Escribir se torna una ocupación sin identidades, el Macedonio Fernández creía que por medio de su literatura de la nada el lector podia llegar a sustraerse de la muette. Al eliminar su fe en la lógica y en el sentido común, el lector suspenderá también la creencia en su yo finito. La muerte, entonces, perdería toda importancia, Macedonio quiere librar al lector de la noción de muerte y cree que haciéndolo, lo sustraetá de la muerte misma. Este tipo de pensamiento abunda en su obra, sobre todo en su libro No toda es vigilia la de los ojos abiertos (Buenos Aires: Centro Editor de América Latina, 1968). p. 8 .

15 Julio Cortázar, 62. Modelo para armar (Buenos Aires: Sudamericana, 1968),

16 E1 sưño de una literatura sin autores reaparece en Borges. En "Tlön, Uqbar, Orbis Tertius" (Ficciones, Buenos Aires: Emecé, 1956), se conjetura un mundo donde la invención de autores es obra de la crítica, un ejercicio de psicología: "No existe el concepto de plagio: se ha establecido que todas las obras son obra de un solo autor, que es intemporal y es anónimo. La crítica suele inventar autores: elige dos obras disímiles - el Tao Te King y las 1001 
un gigantesco espacio formado por los libros que el escritor lee al of recer su propia obra, una biblioteca re-escrita y releída:

En el trastorno de acomodar el nuevo cuartel se me han escondido o amotinado Quievedo, Mark Twain y demás colaboradores de mis colaboraciones a la "Revista Oral"; no encuentro ninguno de los libros y autores que yo más escribo, y hasta que no ordene toda la biblioteca no recobraré mi inventiva. (PR, P. 94)

\section{B. EL TIEMPO}

Vimos que en la obra de Macedonio los juegos con el espacio tienden a crear una textura literaria antirrealista que rehusa ser obra de un solo autor, $\mathrm{y}$ un mundo cuyos elementos presentan propiedades de cambio distintas de las habitualmente reconocidas. Estas características se complementan con la burla del tiempo.

El porvenir, la idea de aquello que se avecina pero cuya característica principal es el no-ser-todavía, es centro de los juegos desmentidores del tiempo:

Dura en el público lo que en mi casa y entre mis conocidos nunca empezó: una reputación que me figura como escritor y como el único que tiene completo el porvenir, todo por hacer (no habiendo hasta ahora escrito nada futuro) y puede empezarlo por donde quie. ra como a pastel redondo que siempre aciértase morderlo donde principia. (PR, p. 101)

Una carta dirigida al director de Proa que figura en Papeles de recienvenido es un excelente ejemplo del modo como Macedonio cuestiona el tiempo y elabora sobre la noción de porvenir. La carta es escrita para formular interrogantes a propósito de la inminente clausura de Proa, que no publicará más colaboraciones de sus escritores como resultado de 1) su futura ausencia:

Colectando con la cucharita algo de azúcar y de líquido hago a usted mi Director una pregunta: ¿Los números que no aparezcan serán más fáciles de dirigir o al contrario será como cuando un "completo" se hace mantel y las puntas líquidas avanzantes ani-

Noches, digamos-, las atribuye a un mismo escritor $y$ luego determina con probidad la psicología de ese intẹtesạnte bomme de lettres..." (p. 27). 
madas de un gusto sin prevenciones por todas las posiciones y rumbos del espacio se tiendan tan prontas $y$ divididas que no hay que pensar en dirigirlas, tanto más cuanto que, lo primero que han hecho es suscribir vuestro pantalón claro a su acontecimiento y preparar una semana de prosperidad para las tintorerias en todos los trajes vecinos, a cuyo socorro hay que acudir ante todo? (PR, pp. 30-31)

El porvenir está también calificado, pobiado de posibilidades que se asemejan a las de un café volcándose sobre el mantel. Una revista que no sale más estará ausente durante todo el porvenir. Su ausencia podría ser dirigida y calificada: el porvenir de aquello que deja de ser es especifico y poblado de atributos. Ia anulación que implica la inexistencia es, para Macedonio, posibilidad de ser en un tiempo distinto. ¿Cómo es tal tiempo? Es su propia negación: la eternidad:

¿Parece que Proa está bastante lázarocosta y que entre este número y el próximo podrá circular holgadamente la Eternidad? (PR, p. 30)

El tiempo de la existencia de Proa es, según Macedonio, reversible. Puede pensarse como un guante que posibilita la lectura de lo ausente:

Si a Proa la hubieran hecho darse vuelta, concluida su primera existencia, podría ahora empezar a vivir del lado del revés. (PR, p. 30)

El Calendario es un modo de admisión del tiempo. Creer en los almanaques significa aceptar un orden, aumir una perspectiva ante la realidad: Confundir el almanaque con el tiempo mismo, y suponerlo real e inamovible en vez de arbitrario y convencional, es uno de los modos de experimentar el mundo que Macedonio quiere cambiar. En un texto titulado "La nada de un viaje de Colón", Macedonio elabora la duda acerca del tiempo al cambiar y sugerir imposibilidades sobre las fechas dadas por los historiadores:

Colón se encontraba en Italia cuando nació. Aunque esto le ocurrió a Colón, como a todos los hombres, en un día y año, la fecha exacta no la tenemos hoy: se habrá echado a perder por no haber sido guardada en un lugar seco y frío; lo cierto es que hay hom- 
bres poderosos o ricos o de celebridad que no disponen de esa fecha que los más humildes de Génova la supieron de memoria ịnstantes después. Sólo hay de cierto que el hecho ocurrió en uno de los días de su primer año de existencia y que el día de su nacimiento fue $\tan$ exacto como el mejor del año en exactitud. Es una fantasía incomprensible, una teoría a la que nada de tonto le falta, sostener que nació en un dia inexacto como alegar que nació en varios lugares: dos o tres de España y uno de Italia, además del de nacimiento. (PR, PP. 125-26)

La creencia rigida en un orden inalterable es cuestionada por el tratamiento de las fechas como objetos a los cuales se les puede atribuir descomposición por temperaturas inconvenientes o posesión por personas. La enumeración de las teorias que rechaza - la posibilidad de varias fechas de nacimiento, distintos lugares de realización del suceso- implicauna actitud de credulidad que de por sí crea un absurdo.

Esta idea de Macedonio acerca del tiempo y los juegos en que considera su ordenación en calendarios y relojes como algo permutable por otras realidades, reaparece asiduamente en la obra de Cortázar. El ejemplo más claro de tal reaparición se encuentra en Historias de cronopios $y$ de famas: el cuento del reloj-alcachofa cuyo tiempo consistía en la duración de sí mismo mientras era inevitablemente comido. ${ }^{17}$ En "Conducta de los espejos en la isla de Pascua"18 hay espejos que atrasan o adelantan según la posición en que son colocados. Funcionan sin ningún método claro y marcan el tiempo arbitrariamente mientras reflejan realidades a veces cercanas, y otras distantes. En "Preámbulo a las instrucciones para dar cuerda al reloj" y en "Instrucciones para dar cuerda al reloj", ${ }^{10}$ Cortázar sugiere una relación de inferioridad del hombre con respecto a su reloj; el dueño del reloj imita a su posesión y cumple temerosamente todas las funciones destinadas a su conservación: "No te regalan un reloj, tú eres el regalado, a ti te ofrecen para el cumpleaños del reloj".20

Uno de los objetivos que Macedonio perseguía con sus juegos eta mostrar las oposiciones latentes, destacar la posibilidad de un mundo con leyes distintas donde los objetos que consideramos fundamentales cumplieran funciones diferentes de las habituales. Este es el mismo sentido que los juegos con relojes tienen en la obra de Cortázar.

\footnotetext{
17 Ver en la edición ya citada de Historias de cronopios..., "Relojes", p. 124.

18 Historias de cronopios..., p. 67.

19 Historias de cronopios..., pp. 27.29.

20 Historias de cronopios..., p. 28.
} 
Vimos que los juegos con el espacio afectan al espacio literario; los del tiempo revierten también sobre la escritura. Esto es evidente tanto en Papeles de recienvenido como en Museo de la novela de la Eterna. La Eterna es la hipótesis que sitúa el transcurrir de la novela en un ámbito donde éste se anula. La Eterna impide el suceder, fija la acción, cristaliza los momentos. Esta función es complementaria de la crítica al realismo. La falta de suceder surge de la carencia de argumento. No hay desarrollo en la novela de Macedonio; no existe desplazamiento temporal. Estas características son, para Macedonio, las de la novela en estados:

La escuela artística que ha de dominar pronto, al reinar la máxima severidad de arte, cultivará únicamente la novela en estados, un como melodismo sin música del sucederse los estados que trasuntan los capítulos, una como metáfora de lo que se sintió en cada tiempo de la novela (MNE, p. 234)

Se trata de hacer una novela compuesta de metáforas, de una constelación de imágenes separadas y unidas al mismo tiempo por la ausencia de temas y referencias al mundo. Maçedonio no pensaba que Museo de la novela de la Eterna fuera el logro de ese objetivo. Constituía la formulación de que tal literatura era posible. La idea de la novela en estados, de Macedonio, guarda relación con 62. Modelo para armar de Julio Cortázar en muchos aspectos. En el programa novelístico que Morelli esboza en el capítulo 62 de Rayzela uno de los rasgos más destacados es la impersonalidad de la novela proyectada. Se trata, como en la literatura de Macedonio, de eludir la definición psicológica tradicional de personajes $\mathrm{y}$-nos dice Morelli y también Macedonio- la hechura de personajes individuales. En ambos casos encontramos el deseo de evadirse de la novelística tradicional por medio de un rechazo del tratamiento lineal del tiempo, la definición individual y psicológica de los personajes y la fijación de acciones en un espacio que refleje el geográfico. El proyecto de Morelli se concreta en 62. Modelo para armar y el de Macedonio queda absorbido en su propia formulación, en la ambigüedad formada" por el carácter heterogéneo del texto: programa estético a ratos, aplicación y concreción de una novelística en otros.

\section{c. Causalidad y ocupaciones}

Cuando Macedonio decía que quería conmover la fe en la lógica, en un ordenamiento férreo de los sucesos, pensaba en alterar la fe en el tiempo, en el espacio y también la creencia de que unos hechos provocan 
otros. Su tarea de subvertir la confianza en el sentido común tomó como blancos ciertas zonas donde rigen principios diariamente experimentados por la mayoría como inamovibles. Uno de ellos tiene estrecha relación con su tratamiento del tiempo: Macedonio combate enfáticamente la creencia popular en la necesidad de la muerte:

La muerte natural (sin violencia química, mecánica, infecciosa, de fatiga, de temperatura, hambre o sed, etc.) no es forzosa; y existe todavía porque nunca se ayudó del todo a un viejo.

En todo día hay tiempo para "ganarse un día siguiente" de exis-" tencia; un viejo ayudado del todo tiene siempre el día siguiente $y$ no pide más eternidad que eso. ( $P R, p .142$ )

Cuando Macedonio habla de luchar contra la causalidad deja la puerta abierta para justificar y crear nuevas ocupaciones. La necesidad de éstas es postulada con total seriedad. Recordemos la frase de Lenin que inicia Ultimo round: "Hay que soñar, pero a condición de creer seriamente en nuestro sueño, de examinar con atención la vida real, de confrontar nuestras observaciones con nuestro sueño, de realizar escrupulosamente nuestra fantasía". Macedonio enumera tareas absurdas con total seriedad y ese tono es su arma crítica en contra del espíritu de seriedad. Por ejemplo:

Desde que dejé olvidado mi perro, colgado en una percha del vestíbulo o metido en el paragüeto de una casa que visitaba, decidi reemplazarlo por una ornato-compañia más inseparable, pues personas de mucho éxito en la retención de sus varitas garantízanme no recordar caso alguno de olvido de bastón, aparte de otros inconvenientes que no se promueven entre bastones en los vestíbulos y si entre perros. ( $\mathrm{PR}$, p. 21)

En el contexto que crea Macedonio resulta perfectamente aceptable la hipótesis de dar a un perro y a un bastón usos idénticos. El tono neutro del texto implica una equiparación entre ambos elementos; al hacerlo elimina la diferencia entre el sentido común y la excentricidad. Se ha establecido una escala donde reina la ambigüedad y la disponibilidad. A ese: mecanismo se refería Macedonio cuando hablaba de destruir la causalidad. Y también a ese mecanismo se refiere Cortázar en los numerosos textos en que habla del sentimiento de lo fantástico: 
Pero ahora pasa que el hombre-niño no es un caballero sino un cronopio que no entiende bien el sistema de lineas de. fuga gracias a las cuales se crea una perspectiva satisfactoria de esa circunstancia, o bien, como sucede en los collages mal resueltos, se siente en una escala diferente con respecto a la de la circunstancia, una hormiga que no cabe en un palacio o un número cuatro en el que no caben más que tres o cinco unidades. ${ }^{21}$

En Historias de cronopios y de famas, Julio Cortázar nos presenta una peculiar familia de la calle Humboldt que se entretiene con ocupaciones extrañas. Los vemos tomar una seccional de correos, confundir los trámites; concurrir a velorios y organizarlos; construir patíbulos. La obra de Cortázar abunda en personajes y en situaciones que revelan ocl. paciones fuera de lo común. Estos juegos con la realidad cotidiana son alternativas de vida que debilitan la fe en un orden único y férreo de existencia. Macedonio practicaba constantemente esta literatura. La materialización de su nada era, sobre todo, sugerencia de tareas absurdas, inventos nunca antes necesitados, imaginación de mecanismos:

Pero no todo lo tengo en el porvenir: prueba de ello es el ingenio seguido y constante que he mostrado siempre que pude para la invención de mecanismos: la solapa desmontable, los agujetos de un solo lado para manteles que tengan dos, la inviolabilidad de las llaves, la extirpación del intervalo soleado entre la salida con paraguas y el empezar a llover, el volvedor de los libros y de los días que fueron buenos, el dispositivo de descomponer juguetes que disimulará para siempre la morosidad de los niños efectuarlo, un bajoparlante que hace del hogar y del amor de hogar un agradable estar fuera de casa, donde el altoparlante impera incesante; (aplicado el bajoparlante a casos individuales y momentáneos me servía para no oír la voz de mis tías cuando volvía tarde a casa, obraba un milagro de silencio que llegaba hasta el silencio de tía, nunca antes conocido; se callaban como si fueran ellas las que hubieran gozado de haber estado libres de ellas - si yo les soy. molesto, cómo lo serán ellas consigo mismas - todo el día fuera de la casa y de volver tarde), los tranvías sin lugar para perder paquetes, las reputaciones sin el reverso, el paraguas meteorológico convertible en sombrilla (aparte del bastón), porque a los meteorólogos no les gusta el ridículo cuando llevan en la mano

21 La vuelia al dia en orbenta mundos, p. 22. 
lo contrario de lo que se ha puesto el cielo para vestir en ese momento. (PR, PP. 101-102).

Este texto quiere suscitar en el lector la sospecha de un orden opuesto a aquel donde vive. Poder proponerse los inventos de Macedonio significa dejar de lado la confianza en tareas diariamente justificadas, iniciar otra perspectiva. Este fragmento, donde se enumeran tareas que no existen ni parecen necesarias en la vida cotidiana, elabora un ámbito donde la ausencia - aquello que no está- está omnipresente. Al sugerir otros intereses y enfatizar esta suerte de reverso del mundo, Macedonio libra su batalla contra la causalidà y la lógica.

\section{Humor y Mundo Fantástico}

Los juegos de realización de la ausencia de Macedonio Fernández son numerosos y abarcan desde los que tienen tiempo, causalidad y espacio como blanco, hasta los más directamente abstractos de conceptos y números que crean, por sí, contextos vacios. Macedonio hablaba de una "conmoción espiritual", de un "tropezón conciencial" que la lectura de esta literatura de la ausencia podía llegar a provocar en los lectores. El acto de leer, de poseer un universo que es el reverso del real, conduciría a la creación de una nueva clase de lectores. No el lector que busca la proyección personal, el retrato de aspectos de la realidad que él mismo ve todos los días, sino el lector capaz de despojarse de su identidad, su sentido común, su lógica. Esta tarea es, para Macedonio, únicamente posible por medio de la literatura. Aunque Macedonio no llegó a elaborar demasiado sobre las razones que le hacían ver a la literatura como el medio más idóneo para alcanzar sus objetivos, hay ciertas afirmaciones implícitas en su actitud.. La palabra escrita es, para él, un elemento que admite gran variedad de juegos que permiten escapar de la referencia a ámbitos extraliterarios. Hay la posibilidad de crear una escritura totalmente autorreflexiva. Así, ese mundo que Macedonio llamaba fantástico es el de la red formada entre sus textos y la experiencia de lectura. Con el humor absurdo el lenguaje escrito muestra sus características convencionales y coloca al lector en una posición de duda con respecto al lenguaje en general. Ese espacio de ambigüedades donde las organizaciones de lo percibido son vistas en su carácter convencional preparan el terreno para la aceptación de una realidad más amplia y contradictoria. Macedonio siguió consistentemente las consecuencias de su sueño. Suponía que del estado de inquietud, de extrañamiento, que 
su literatura provocaría en los lectores surgiria una nueva sensibilidad, nuevas formas de existencia. Cortázar comparte esta actitud de Macedonio según la cual el humor adquiete el papel importantísimo de juego transformador de la realidad. En Cortázar y en Macedonio el mundo fantástico no está prolijamente separado del cotidiano. Hay una constante gravitación de uno sobre otro. Destacar la posibilidad del absurdo, crearla en los textos es, para ambos, una manera de agresión contra la realidad convencional: un acto de apertura.

La figura de Macedonio reaparece ahora, siempre actual, en una relectura de Cortázar, de Borges, de Bioy Casares, de Marechal. Esta reaparición y la relativa oscuridad acerca de su persona de escritor seguramente le hubiera agradado a Macedonio: es el sueño de un continuo literario sin autores individuales, la consecución de una obra abierta.

The Johns Hopkins University 
